http://dx.doi.org/10.30681/23588403v12i032537

\title{
LÍNGUA E IDENTIDADE: ADAPTAÇÃO LINGUÍSTICA NA FRONTEIRA BRASIL/BOLÍVIA
}

Edenilson Jacinto ARAÚJO (UNIR) ${ }^{1}$

Data de recebimento: $18 / 04 / 2018$

Aceite: 26/06/2018

\begin{abstract}
Resumo: O presente artigo é um estudo de caso cujo objetivo foi analisar, demonstrar e compreender como o contato linguístico afetou na fala dos indivíduos que são submetidos a diversas situações de interação com línguas diferentes. A pesquisa é qualitativa e apresenta qual a adaptação linguística de um migrante boliviano que reside no Brasil há mais de cinquenta anos e como ele mantém vivo traços de sua língua materna mesmo convivendo em um país com diferenças culturais e sociais. Como norteadores para esta pesquisa, foram utilizados os seguintes autores: SILVA (2007), TARALLO \& ALKMÍN (1987), CALVET (2002). A abordagem feita revela as consequências do contato linguístico na região de fronteira Brasil/Bolívia, na cidade de Guajará-Mirim/RO, no bairro do Triângulo. Ao decorrer das análises, serão notados, na ótica das fundamentações teóricas, os fenômenos linguísticos que surgiram na fala, trazendo do particular para o geral.
\end{abstract}

Palavras-Chave: Identidade. Língua. Adaptação.

Abstract: This article is a case study whose objective was to analyze, demonstrate and understand how the linguistic contact affected in the speech of individuals who are submitted to different situations of interaction with different languages. The research is qualitative and presents the linguistic adaptation of a Bolivian migrant who has lived in Brazil for more than fifty years and how he keeps alive traces of his mother tongue even while living in a country with cultural and social differences. As guiding principles for this research, the following authors were used: SILVA (2007), TARALLO \& ALKMÍN (1987), CALVET (2002). This approach reveals the consequences of linguistic contact in the border region of Brazil / Bolivia, in the city of Guajará-Mirim / RO, in the Triângulo neighborhood. Throughout the analysis, the linguistic phenomena that have emerged in the speech, from the particular to the general, will be noticed from the point of view of the theoretical foundations.

Keywords: Identity. Language. Adaptation.

\section{Introdução}

Este trabalho apresenta resultados de uma pesquisa realizada no município de GuajaráMirim, tendo como como fonte de dados um migrante boliviano com 77 anos de idade e que reside no município há mais de 50 anos, especificamente, no bairro triângulo, situado às margens do rio Mamoré que faz divisa com a Bolívia.

\footnotetext{
${ }^{1}$ Graduado em letras, pela Universidade federal de Rondônia. Guajará- Mirim, Brasil. E-mail: edenilson.arajo@yahoo.com.br.
} 
Por ser um local com uma grande presença de habitantes bolivianos oriundos desse fluxo migratório, entender os fatores sociais que levaram essas pessoas a migrar para o Brasil, o que ocorreu com esse contato linguístico e como ocorre o processo de comunicação entre migrantes bolivianos e brasileiros são pontos de suma importância e relevância para o entendimento da temática da adaptação linguística.

Para fundamentar as discussões apresentadas, foram utilizadas as teorias da sociolinguística que é a ciência que estuda a língua num contexto social, ou seja, os fatores externos e internos num determinado grupo social que contribuem para possíveis mudanças na língua com a qual se comunicam, e também de elementos fonéticos e fonológicos, para de forma bem clara, apresentar como funciona a comunicação dos migrantes bolivianos e brasileiros na prática utilizando ilustrações.

Como fundamentações teóricas para esta pesquisa, foram utilizados os seguintes autores: SAUSSURE (1916), LABOV (2008), BAGNO (2014) que trazem em suas obras os conceitos básicos de língua/linguagem, também temos TARALLO \& ALKMIN (1987), CALVET (2002) todos esses teóricos auxiliaram diretamente nos resultados dessa pesquisa, bem como, nortearam e deram caminhos e suporte, ou seja, fundamentação e embasamento para se tornar possível os resultados da pesquisa.

Pretende-se com a apresentação dos resultados, colaborar para que se compreenda os fenômenos que ocorrem na fala de um migrante boliviano e assim os fatores possam ser apresentados e divulgados tornando a relação brasileiro/boliviano na fronteira mais amena e a comunicação seja vista como um processo de adaptação linguística na fronteira Brasil/Bolívia.

\section{O sujeito do discurso}

Entrevistamos o informante, migrante boliviano, casado, natural da província de San Rafael na Bolívia, de 77 anos de idade, que possui apenas a $2^{\circ}$ série do ensino fundamental no sistema educacional boliviano, legalizado perante as instituições de controle migratório, que reside no Brasil há mais ou menos 54 anos. Esse é um retrato típico da situação social e econômica que vivem os cidadãos bolivianos, pois, de acordo com o informante, eles eram submetidos a duras cargas horárias de trabalho para receberem um capital que mal servia para suprir as suas necessidades mais básicas, sendo este um dos fatores que influenciaram no seu processo de migração para o Brasil em busca de emprego e condições dignas de sobrevivência. 


\section{A pesquisa (dados e análises)}

\subsection{Manutenções lexicais.}

Chegando ao Brasil, o informante teve por necessidade, se inserir culturalmente e socialmente, bem como conviver com costumes e uma língua diferente. Diante do contato linguístico, o informante foi obrigado a adaptar-se linguisticamente, e por trabalhar em uma embarcação que fazia transporte ribeirinho de Guajará-Mirim à Pimenteiras/RO, que é um município do estado de Rondônia, teve por necessidade realizar comunicações com os tripulantes da embarcação que eram brasileiros, dessa forma o informante começou a internalizar palavras e expressões da língua dos companheiros de trabalho (português), onde na sua concepção mental, ele construiu frases e diálogos e foi enriquecendo o seu léxico, porém, sem deixar que sua marca linguística de falante boliviano desaparecesse, ocorrendo assim, o fenômeno de mescla lingüística.

A mescla linguística "[...] é mistura, contato, amálgama, etc." (TARALLO \& ALKMIN,1987, p.7), demonstrando claramente na sua obra, que ocorre a mistura das línguas, e com isso, podem ocorrer duas coisas: as línguas podem conviver harmoniosamente uma com a outra sem haver a mistura, ou pode acontecer dessas línguas se cruzarem, ocorrendo a mistura, e como resultado dessa mistura, há uma hibridização da língua, que pode ser entendido como falantes que se utilizam tanto elementos de sua língua materna de origem como elementos da língua em que obtiveram o contato. Com base nessa teoria, entende-se que o informante teve por resultado do contato linguístico, essa mistura ou mescla do Castelhano (que é um dialeto da língua espanhola), com o português (que é a língua materna do Brasil), gerando assim, uma transformação na sua fala, onde permanece o sotaque e idioletos em castelhano com palavras em português.

Além disso, um dos pontos-chaves do modelo sociolinguístico é o fato de o espaço da mescla linguística ser a comunidade de fala. Ou seja, é nas comunidades de fala ou entre elas que se concretizam diversos tipos de contato, os quais produzem, por sua vez, fenômenos de mescla ou de convivência/coexistência, mecanismo esse ativado pelos indivíduos que integram tais comunidades. Chegamos, assim, a uma distinção fundamental: a mescla intracomunidade (isto é, variantes convivendo e//ou se entrecruzando em uma mesma comunidade de fala, em que somente uma língua é falada: o português, por exemplo) versus a mescla intercomunidades (ou seja, línguas distintas coexistindo e se misturando em uma mesma comunidade: por exemplo, o caso de o português conviver com o alemão, o 


\section{Revista de Estudos Acadêmicos de Letras}

polonês e o italiano na região sul do Brasil). (TARALLO \& ALKMIN, 1987, p.9)

O que ocorreu com o informante, foi o fenômeno da mescla intercomunidade, em que línguas distintas convivendo em uma mesma comunidade se cruzaram misturando-se e como consequência disso, naturalmente, ocorre um processo de modificação na fala devido a esse contato linguístico. Porém, o que foi notório perceber no informante, é que mesmo ele se deslocando para um País culturalmente e socialmente diferente do dele, mantendo na sua fala elementos fortes da sua língua materna, pois, apesar de residir no Brasil há muito tempo, observa-se uma marca bem contundente de palavras que o informante traz em sua fala, e que sobrevive apesar de tantas influências dos falantes do português.

Verifica-se que apesar do informante ter por necessidade se utilizar do português para se comunicar com os brasileiros, ele manteve de forma bem característica, traços da fala de sua língua de origem, levando ao entendimento que nessa relação de contato, as línguas coexistem entre si, não havendo um desapego da sua língua materna, pois o informante não teve por necessidade abandonar sua condição linguística de origem para se tornar um falante do português. A partir da realização de entrevista com o informante foi possível verificar a manutenção de algumas palavras de origem castelhana na sua fala como, por exemplo:

Quadro $1^{2}$ - Manutenções lexicais.

\begin{tabular}{|c|c|}
\hline Espanhol & Português \\
\hline A si & Assim \\
\hline No & Não \\
\hline Donde & Onde \\
\hline Educación & Educação \\
\hline Tambien & Também \\
\hline Cosa & Coisa \\
\hline Injeción & Injeção \\
\hline Alla & Lá \\
\hline
\end{tabular}

Essa manutenção pode ser percebida através do fenômeno de mescla intercomunidade como: fusão, troca e adaptação, dentre outros, como por exemplo na frase: [...]Por isso que o pessoal me conhece quando eu tô falando asi,eles falam asi há você é boliviano?[...] Bem como também na frase: [...] no posso me negar[...] que se torna evidente na forma de

\footnotetext{
${ }^{2}$ Os registros encontrados foram transcritos de maneira aproximada.
} 
comunicação do informante, pelo fato de estar inserido em uma comunidade de fala, onde por questões naturais de contato, utiliza-se de elementos da língua dominante, sempre prevalecendo a língua de maior influência, ou também, pode ocorrer à manutenção dos dois sistemas linguísticos, e em nosso caso, é o convívio de um falante de língua espanhola, tendo que conviver no Brasil, e sofrendo duras influencias da língua portuguesa há muitos anos.

A manutenção lexical ocorrida na fala do informante demonstra como fatores culturais se tornaram elementos fundamentais para que os traços da sua língua materna (espanhol) ficassem bem presentes no desenvolvimento da sua fala, tornando-se um ponto fundamental para se compreender como o informante mantém viva as características de sua fala, mesmo sendo forçado a desenvolver de forma cognitiva a comunicação, utilizando-se dos elementos lexicais da língua portuguesa, e diante disso, é notório perceber como as palavras do léxico do informante que surgem naturalmente em uma situação de fala corriqueira, tendo por consequência a permanência de palavras em espanhol quando ele, em um diálogo, fala em português, mas em determinado momento ele mantém palavras em espanhol. Como afirmam os autores

Diferentemente da situação de diglossia, em que a escolha do código a ser usado (inglês ou Frances, por exemplo, no Canadá) é ditada por domínios de discurso, em code - switching os dois sistemas se mesclam no nível da sentença. (TARALLO \& ALKMIN, 1987, p.13)

Tarallo \& Alkimin (1987), demonstram como esse código de troca funciona na prática, a partir de um exemplo: suponhamos que em determinada região do Brasil, o português se alternasse com o Alemão, o resultado disso segundo os autores é a ocorrência de frases em que os alemães falariam em português, mas terminaria a frase falando palavras em alemão, sua língua materna. Partindo desse princípio, podemos entender como na fala do informante, que é boliviano falante de língua espanhola, que convive na fronteira Brasil/Bolívia e reside a mais ou menos cinquenta e quatro anos no Brasil, ocorra esse processo de troca de código, pois o informante por ser bilíngue, conservou em sua fala esses códigos, que diante de uma situação de diálogo, surgem naturalmente e se alternam na medida em que ocorrem as construções das sentenças na sua mente, e por esse motivo, as palavras da língua materna do informante surgem na sua fala como uma marca evidente da mescla intercomunidade, onde as duas línguas coexistem em uma mesma comunidade se misturando à medida que elas entram em contato. 


\section{Revista de Estudos Acadêmicos de Letras}

Independentemente da configuração levemente diferenciada entre mescla inter e intracomunitária, o que na realidade está em jogo são fatores sociais, históricos e políticos, como grau de segregação e de integração das comunidades em questão. (TARALLO \& ALKMIN,1987, p.61)

Com essa afirmação, os teóricos colocam o fenômeno de mescla linguística, como um fator preponderante para a integração das comunidades em que ocorra o convívio de línguas coexistindo em uma mesma região, e também, as variantes ocorridas em uma língua de uma determinada região, apontando assim, que a consequência maior são fatores sociais, histórico e políticos afetados por fenômenos linguísticos, onde certa comunidade em que convivem falantes biligues pode ocorrer fatores de mistura de línguas, e consequentemente, sua cultura pode ser afetada, podendo ocorrer assim, em uma comunidade monolíngue, uma língua prevalecendo e tendo como resultado a extinção da outra, e desaparecendo uma língua e sua cultura, desaparece sua história, por isso, esses fenômenos são de extrema importância para os estudos linguísticos.

Seguindo essa mesma linha de pensamento, pode-se notar no informante boliviano, teve um cuidado em manter vivos traços de sua cultura, e na forma do seu sotaque, percebemos como ser boliviano é importante pra ele, mesmo inserido em uma cultura diferente de convívio, sua marca linguística prevalece, isso é notório através do seu léxico, pois podemos perceber palavras enraizadas no seu vocabulário mental, sendo conservadas e utilizadas no seu convívio social com os brasileiros, e percebe-se no informante, que a manutenção das palavras e a forma de falar característica da sua terra natal nos revelam como fatores externos a linguagem afetam todo um contexto linguístico.

O fenômeno da mescla linguística, tal qual brevemente esboçado no capitulo anterior, revela-se a principio (e quase por definição) como algo altamente instável. De fato, ao misturarmos uva preta com branca, nenhuma receita poderá nos garantir quão rosado ficará o vinho. Se quisermos, por exemplo, um vinho rose mais claro, nosso senso comum (e talvez a própria receita) nos ditara uma quantidade maior de uva branca; ao contrario, conforme nos diz a intuição e a receita, um vinho rose mais para o tinto irá requerer como ingrediente básico a uva preta. De qualquer forma, parecem ser os elementos externos à natureza da uva em si que acarretam o resultado final desejado: rose mais claro ou mais escuro. E nesse sentido que dizemos ser a mistura um fenômeno instável. A estabilidade do fenômeno somente será alcançada pelo acionamento dos tais elementos externos. São estes que exercem um controle sobre a mistura de diferentes tipos de uva de forma que se obtenha o vinho desejado. (TARALLO \& ALKMIN,1987, p.19)

Segundo Tarallo \&Alkmin (1987), o processo de mescla linguística é instável, ou seja, não se pode prever o que ocorrerá diante de um contato linguístico, e quais consequências 
seria resultado desse fenômeno, não podendo assim afirmar como e de que forma ocorrerá essa mistura, e de forma bem clara, os teóricos citam como exemplo, a mistura de uvas brancas e pretas para se produzir um vinho rose mais claro ou mais escuro, onde só se pode definir que ele ficará mais escuro se acrescentarmos mais uvas pretas do que brancas, não sendo possível deixar esse papel com a uva, pois ela é instável em seu resultado, não podendo se definir se ela vai deixar ou não o vinho rose mais escuro ou mais claro.

Dessa mesma forma, na situação de contato linguístico, ocorreu instabilidade na fala do informante, pois ao invés de prevalecer o português como fluência devido ao seu tempo de convívio no Brasil, o que se pode notar foi uma mistura, e por consequência sua identidade linguística sofreu alterações, mas não perdendo as características fundamentais que demonstram que ele é falante de língua espanhola. Partindo desse princípio, entende-se como em meio a tanta influência na sua fala, o informante manteve uma porcentagem boa de presença de sua língua materna na sua fala, sendo assim, perceptível a manutenção lexical na interação com os brasileiros que pode ser mais bem compreendido como palavras que mesmo diante da instabilidade ocorrida no fenômeno de contato prevaleceram mesmo diante da forte influência causadas pelo sistema linguístico do português.

O que Tarallo \& Alkmin defendem é que na mescla ou mistura das línguas, não se pode definir o que vai acontecer, podem ocorrer perdas de sotaque, podem ocorrer o desaparecimento do bilinguismo devido a possível extinção de um dos sistemas linguísticos, podem ocorrer misturas e cruzamentos que favoreçam uma língua, mas com presença da outra, sendo possível encontrar estabilidade nos fatores externos a língua como, por exemplo, um falante de língua Francesa que não possua vínculo patriótico com seu país, mas deseje se naturalizar e habitar na Inglaterra, estará condicionando sua fala para se ater exclusivamente a língua inglesa, e o resultado disso com o passar do tempo, é um falante monolíngue, que decidiu abrir mão da língua materna.

Por essa razão, é que o informante se mostra firme na sua realidade cultural e patriótica, e com a permanência de elementos lexicais na sua fala, demonstra que foi resultado de um fenômeno, mas por questões extralinguísticas, preferiu levar consigo as marcas linguísticas de sua terra natal, mesmo convivendo em um país diferente do seu, escolheu manter viva as suas origens em sua maneira de falar.

3.2 Construções sintáticas na fala do informante. 
Serão também os homens e as suas culturas, suas línguas, sua sintaxe e sua fonologia afetados por fenômenos de contato, mistura, alquimia e mescla? É obvio que sim! Também as diferentes maneiras de falar, sintaxes e fonologia diferenciadas, línguas distintas ou coexistem à medida que se compartimentalizam com vistas às suas respectivas funções sociais, ou se cruzam, combatendo-se umas às outras pela conquista de um espaço social próprio. É, portanto, somente através do convívio social dessas chamadas diferentes maneiras de falar que elas se justificam como veiculo efetivo de comunicação entre os falantes da comunidade. (TARALLO \& ALKMIN, 1987, p.9)

Em relação às construções sintáticas, Tarallo \& Alkmin (1987) trazem a afirmação de que, o contato linguístico, afeta e muito as estruturas das expressões e frases utilizadas por um falante em uma comunidade onde ocorrem cruzamento e mistura das línguas, e isso é explicado pelo fato de ambas as línguas disputarem espaço dentro da comunidade, medindo forças para adquirir a soberania em relação a influência dos falantes na sua comunicação e interação dentro da comunidade. Com base nisso, é possível perceber na fala do informante, características bem particulares no momento da construção de frases e orações, ou, até mesmo, expressões, ou seja, para ele poder se adaptar, teve que aprender a montar frases com objetivo de gerar sentidos e ser entendido no processo de comunicação, uma prova bem clara de como o contato linguístico afetou a sua sintaxe de forma brusca lhe obrigando a internalizar códigos de sentenças pré-progamados, e com isso, nascendo em sua maneira de expressar palavras agrupadas em uma situação de dialogo, sem se preocupar com a organização das funções das palavras dentro das frases.

Um exemplo claro das alterações nas construções sintáticas ocorridas na fala do informante é perceptível em resposta a uma simples pergunta:

\section{Pesquisador: $O$ que você acha da educação no Brasil?}

Informante: Bom, por mim os meninos deviam ter aprendido mais [...]

Observa-se claramente que a preposição "por", está sendo utilizada no lugar da preposição "pra", que seria a melhor opção de uso normal da língua, pois antes do pronome obliquo "mim", se usa a preposição "pra", e o verbo da frase está sendo utilizado na conjugação diferente da que é pedida na frase e para um uso natural se utiliza o verbo "deveriam", pois menciona um ato passado em que ele menciona que os filhos tiveram condições de ter uma educação melhor, porém não aproveitaram a oportunidade de estudar e se formar. Outra frase que podemos analisar é: 


\section{[...] é isso que a gente quer $[\ldots]$}

Nessa frase, o informante por questões naturais de fala, utiliza-se nas construções de suas frases "a gente quer", que no seu uso comum e padrão seria "nós queremos", e por essa construção nota-se claramente, que o informante internalizou expressões de sentido, e se apropria delas nas suas construções sintáticas, ou seja, ele internalizou expressões para cada tipo de situação de comunicação tudo bem pré programado, de maneira que ele satisfaça sua necessidade de comunicação, pois o uso do pronome "nós", é claramente substituído na fala dele por "agente", e o verbo "queremos", é substituído por uma forma verbal totalmente diferente, em que se juntando com "agente" tem um valor de expressão de sentido dentro da construção sintática.Na frase[...] enton aí a gente no gostei [...],pode-se analisar nessa construção, como o informante se apropria da expressão "a gente", para representar o sujeito da oração, e como a mistura das línguas se tornam evidentes na sua fala e nas construções sintáticas, surgem palavras em espanhol na frase e também é notório perceber que ele não consegue distinguir a marcação do pronome do caso obliquo "eu", em substituição a expressão "a gente", no caso de se referi apenas a vontade dele representando algo individual. Esse é o efeito do cruzamento das línguas diferentes dentro de uma mesma comunidade, ocorrendo natural mente as alternâncias de códigos que podem ser traduzidas como, palavras sendo utilizada nas construções em português, mas com a utilização de palavras em espanhol surgindo naturalmente em uma situação natural de fala.

Na sua obra Sociolinguística - uma introdução critica, Louis-Jean Calvet, trata sobre essa temática do contato linguístico traçando alguns pontos essenciais como por exemplo, empréstimos e interferências que ele define assim na sua obra

A palavra interferência designa um remanejamento de estruturas resultante da introdução de elementos estrangeiros nos campos mais fortemente estruturados da língua, como o conjunto do sistema fonológico, uma grande parte da morfologia e da sintaxe e algumas áreas do vocabulário (parentesco, cor, tempo, etc.). (CALVET, 2002, p.35)

Os empréstimos e interferências ocorridos na fala do informante demonstram claramente como as construções sintáticas dele foram afetadas pelo contato entre a língua espanhola e a portuguesa, pois pelo fato do informante ser bilíngue, é possível observar nas construções de suas frases essas interferências que ocorrem naturalmente na sua fala onde o 
teórico chama de interferências causadas naturalmente pelo bilinguismo onde as línguas estão constantemente em contato.

Assim Uriel Weinrich definia em 1953 a interferência, em seu livro, linguages in Contact. Ele considerava que as línguas estavam em contato quando eram utilizadas alternadamente pela mesma pessoa. Podemos distinguir três tipos de interferência: as interferências fônicas, as interferências sintáticas e as interferências lexicais. (CALVET,2002, p.36)

Para Weinrich (1953), as línguas só poderiam estar em contato quando o falante se utilizava da sua língua materna, e por motivos de aquisição ou convívio em uma situação de deslocamento para uma comunidade de falantes de outra língua, teria que internalizar elementos, e por consequência disso, aprende-la, tornando-se assim, um falante bilíngue, mas por questões arbitrárias é obrigado a desenvolver a língua que não é sua primeira, gerando assim as chamadas interferências, pois nessa aquisição de linguagem, naturalmente o falante se utilizara de elementos da sua língua materna no momento em que tiver no processo da fala, sendo ainda mais perceptível nas construções sintáticas, onde palavras são misturadas ou trocadas de posição consequência do contato linguístico.

\title{
3.3 Análise fonética dos dados.
}

Em sua obra fonética e fonologia do Português, Thais Cristofaro Silva define a fonética da seguinte maneira

\begin{abstract}
A fonética é a ciência que apresenta os métodos para a descrição, classificação e transcrição dos sons da fala, principalmente aqueles sons utilizados na linguagem humana. As principais áreas de interesse da fonética são: fonética articulatória - Compreende o estudo da produção da fala do ponto de vista fisiológico e articulatório. Fonética auditiva - Compreende o estudo da percepção da fala. Fonética acústica - Compreende o estudo das propriedades físicas dos sons da fala a partir de sua transmissão do falante ao ouvinte. Fonética instrumental - Compreende o estudo das propriedades físicas da fala, levando em consideração o apoio de instrumentos laboratoriais. (SILVA,2007, p.23)
\end{abstract}

Da mesma forma, ela traz a definição de fonologia trazendo consigo a visão das correntes pós-estruturalistas, sendo exposta da seguinte forma

Correntes teóricas pós-estruturalistas que tratam do componente sonoro são conhecidas como modelos fonológicos. Este capítulo apresenta os principais aspectos e referências bibliográficas dos seguintes modelos fonológicos: fonologia gerativa padrão; fonologia gerativa natural e fonologia natural; 
fonologia não linear: fonologia CV e fonologia autossegmental; fonologia de dependência; fonologia de governo; fonologia lexical; fonologia métrica e teoria da otimização. A interface fonologia- sintaxe é também considerada. (SILVA,2007, p.187)

Diante do contato linguístico ocorrido na fronteira Brasil/Bolívia, o informante teve como forma de adaptação inserida em sua comunicação para com os brasileiros, a utilização de mecanismos ou formas de expressar as palavras de acordo com os sons reproduzidos pelos falantes de língua portuguesa, daí então, o informante foi exposto aos fenômenos linguísticos na sua fala, ou seja, a tentativa de aproximar os sons das palavras no seu aparelho fonador fez surgir eventos naturais como:

Quadro 2 - Transcrição fonética.

\begin{tabular}{|c|c|c|}
\hline Português escrito & Português transcrição & Espanhol transcrição \\
\hline Quase & {$\left[\right.$ ' $\mathrm{k}^{\mathrm{W}} \mathrm{a} \mathrm{z}$ i $]$} & {$\left[{ }^{\prime} \mathrm{k}\right.$ a z i $]$} \\
\hline
\end{tabular}

Na fala do informante foi perceptível encontrar esse tipo de fenômeno linguístico, onde o informante pronuncia a palavra quase de uma forma diferente até mesmo do espanhol, demonstrando certa dificuldade adquirida pelo contato linguístico, em que ele modificou sons como, por exemplo: o /qu/ que é bem parecido nas duas línguas, tanto no português, quanto no espanhol, pelo /k/ que não é uma forma do espanhol e nem muito menos do português.

Na segunda situação na fala do informante, é possível observar outro fenômeno em relação ao contato linguístico que também afetou na produção sonora da palavra que seria a palavra aqui, que ele naturalmente em uma situação de fala, reproduz ela como /acui/ vejamos o exemplo:

Quadro 3 - Transcrição fonética.

\begin{tabular}{|c|c|c|}
\hline Português escrito & Português transcrição & Espanhol transcrição \\
\hline Aqui & {$[$ 'a $\mathrm{k}$ i $]$} & {$\left[\right.$ ' $\left.\mathrm{a} \mathrm{k}^{\mathrm{W}} \mathrm{i}\right]$} \\
\hline
\end{tabular}

É perceptível como o informante reproduz o som da palavra aqui em português, diferente do espanhol, e até mesmo do português. Esse fenômeno de troca de sons é resultado, e fruto das modificações que o falante foi exposto em relação a sua adaptação linguística, afetando de forma cognitiva os sons da sua fala, gerando assim, pontos de articulação diferentes para reproduzir algumas palavras. 
Outro fenômeno notado na fala do informante boliviano, foi a forma de reprodução da palavra gente, que ele faz questão de reproduzir diversas vezes em uma situação de fala, natural acontece uma pequena variação no som, pois em português a palavra gente é expresso pela consoante /G/, e a forma mais aproximada pelo informante foi o /ch/, ocasionando assim um som aproximado do português.

Quadro 4 - Transcrição fonética.

\begin{tabular}{|c|c|c|}
\hline Português escrito & Português transcrição & Espanhol transcrição \\
\hline gente & [' 3 e $\left.n t^{\prime} i\right]$ & {$\left[\int^{\prime} e \mathrm{t}^{f} \mathrm{i}\right]$} \\
\hline
\end{tabular}

Todos esses fenômenos linguísticos, são resultados do contato linguístico que o informante boliviano foi submetido ao se inserir na comunidade de falantes do português, pois, por questões exteriores e alheias a sua vontade, teve por necessidade se adaptar linguisticamente.

\section{Considerações finais}

Compreende-se por meio desta pesquisa, que diante da situação de contato linguístico, os indivíduos dentro de uma comunidade bilíngue, naturalmente através da adaptação linguística, desenvolveram mecanismos que surgem decorrência das necessidades dos falantes de se comunicarem entre si, mesmo sendo de línguas diferentes e inseridos em uma mesma comunidade de fala, trazendo consigo sua língua materna de origem, e sendo-lhe imposta a aquisição de uma língua diferente da sua.

Diante da pesquisa realizada e como resultado da análise dos dados coletados, pode se chegar aos seguintes pontos:

1 - Foram observadas manutenções lexicais na fala do informante;

2 - Nas construções sintáticas foram observados os mecanismos que o informante se apoderou para realizar um processo de comunicação com êxito, sendo uma dessas formas, a internalização de expressões de sentido que agrupadas dão forma a uma frase, satisfazendo sua necessidade no processo de interação com os brasileiros;

3 nas análises, os estudos fonéticos nos revelam claramente todo o processo de adaptação que o informante teve que desenvolver para se comunicar com os brasileiros, e diante de sons produzidos, ele teve por necessidade modificar sons da sua fala e torna-lhes 
parecidos com os sons do português, tendo envolvido nesse processo, toda a estrutura articulatória do aparelho fonador do informante para a realização de tal processo.

Pesquisas como esta, que discutem sobre o contato linguístico nas regiões fronteiriças em que envolvem as questões de língua e identidade, são de extrema relevância para o conhecimento dos fenômenos linguísticos ocorrido na fala dos imigrantes, pois, contribuem para minimizar o preconceito linguístico sofrido por eles.

\section{Referências}

CALVET, Louis-Jean. Sociolinguística: uma visão crítica. Trad. Marcos Marcionilo. São Paulo: Parábola, 2002.

SILVA, Thaïs Cristofaro. Fonética e fonologia do português: roteiro de estudos e guia de exercícios. São Paulo: Contexto, 2007.

TARALLO, F. \& ALKMIN, T. Falares crioulos: línguas em contato. São Paulo: Ática, 1987. 